\title{
Effect of high-flow nasal cannula versus conventional oxygen therapy and non-invasive ventilation for preventing reintubation: a Bayesian network meta-analysis and systematic review
}

\author{
Ling Sang", Lingbo Nong", Yongxin Zheng, Yonghao Xu, Sibei Chen, Yu Zhang, Yongbo Huang, \\ Xiaoqing Liu, Yimin Li \\ State Key Laboratory of Respiratory Disease, National Clinical Research Center for Respiratory Disease, Guangzhou Institute of Respiratory \\ Health, The First Affiliated Hospital of Guangzhou Medical University, Guangzhou, China \\ "These authors contributed equally to this work. \\ Contributions: (I) Conception and design: Y Li, L Sang; (II) Administrative support: Y Li, X Liu; (III) Provision of study materials or patients: L Sang, \\ L Nong, X Liu, Y Xu; (IV) Collection and assembly of data: L Sang, L Nong, Y Zheng, Y Zhang; (V) Data analysis and interpretation: L Sang, L \\ Nong, S Chen, Y Huang; (VI) Manuscript writing: All authors; (VII) Final approval of manuscript: All authors. \\ Correspondence to: Dr. Yimin Li. State Key Laboratory of Respiratory Disease, National Clinical Research Center for Respiratory Disease, Guangzhou \\ Institute of Respiratory Health, The First Affiliated Hospital of Guangzhou Medical University, No. 151, Yanjiang West Road, Guangzhou, China. \\ Email: dryiminli@vip.163.com.
}

\begin{abstract}
Background: Adequate respiratory support can improve clinical outcomes in patients who are ready for weaning from a ventilator. We aimed to investigate the efficacy of respiratory methods in adults undergoing planned extubation using a Bayesian network meta-analysis.

Methods: We searched PubMed, Embase, and ClinicalTrials.gov for unpublished and ongoing trials up to November 2019 for randomized controlled trials (RCTs) published in English that compared conventional oxygen therapy (COT), a high-flow nasal cannula (HFNC), and noninvasive ventilation (NIV) for postextubation respiratory support. Screening of citations, study selection, data extraction, and assessment of risk were performed independently by two authors. The primary outcome was the reintubation rate.

Results: Twenty-two studies (4,218 patients) were included in our meta-analysis. Extubated patients supported with NIV had a significantly lower incidence of reintubation than those supported with COT [odds ratio (OR): 0.63 , 95\% confidence interval (CI): 0.42, 0.89]. However, there was no significant difference in the reintubation rate between the HFNC and NIV, and HFNC and COT groups (OR: 1.05, 95\% CI: $0.60,1.81$; OR: 0.60, 95\% CI: 0.33, 1.02, respectively). HFNC and NIV reduced the incidence of hospital-acquired pneumonia (HAP) (OR: 0.50, 95\% CI: 0.25, 0.93; OR: 0.55, 95\% CI: 0.27, 0.87, respectively) and post-extubation acute respiratory failure (ARF) (OR: 0.35, 95\% CI: 0.14, 0.89; OR: 0.31, 95\% CI: $0.14,0.63$, respectively) compared with COT. There was no significant difference in a decreased incidence of HAP (OR: 1.1, 95\% CI: 0.56, 1.8) or post-extubation ARF (OR: 0.87, 95\% CI: 0.33, 2.1) between NIV and HFNC. There were also no significant differences in improvements in other clinical outcomes, including intensive care unit (ICU) and hospital mortality and the length of stay (LOS) between NIV and HFNC.

Conclusions: NIV reduces the reintubation rate in adult patients undergoing planned extubation compared with COT and HFNC.
\end{abstract}

Keywords: Reintubation; noninvasive ventilation (NIV); high-flow nasal cannula (HFNC); conventional oxygen therapy (COT); meta-analysis

Submitted Feb 26, 2020. Accepted for publication Jun 04, 2020.

doi: $10.21037 /$ jtd-20-1050

View this article at: http://dx.doi.org/10.21037/jtd-20-1050 


\section{Introduction}

Mechanical ventilation (MV) is a lifesaving treatment for patients with acute respiratory failure (ARF). However, delayed MV weaning in patients who are ready for extubation is associated with complications, such as pneumonia, and thus has a negative effect on patients' outcomes (1). That said patients who successfully pass a spontaneous breathing trial may develop ARF after extubation and require reintubation, which is associated with higher mortality and a poorer prognosis $(2,3)$.

Guidelines recommend that preventive non-invasive ventilation should be applied in patients who are considered to be at high risk of extubation failure, with moderate-grade evidence (4). However, a recent meta-analysis showed that this strategy failed to decrease ARF after extubation in the general critically ill population compared with conventional oxygen therapy (COT) (5). Notably, intolerance to noninvasive ventilation (NIV) is also common, and can worsen the patient's outcome (6-9).

A high-flow nasal cannula (HFNC) is a novel device that can provide fully humidified, high-flow oxygen (up to $60 \mathrm{~L} / \mathrm{min}$ ), a constant fraction of inspiratory oxygen, and flow-dependent continuous positive airway pressure (10-12). HFNCs improve patients' outcomes after extubation compared with COT (13-16). However, only $44 \%$ of physicians who completed a recent survey considered HFNC as potentially relevant for improving outcomes in extubated patients (17).

HFNC and NIV can provide adequate respiratory support after extubation However, only two randomized controlled trials (RCTs) $(18,19)$ and one retrospective study (20) directly compared the effectiveness of these two strategies. Both of these trials showed that HFNC was not inferior to NIV in the selected populations. Therefore, the optimal respiratory support strategy after extubation remains controversial.

We performed a network meta-analysis that involved a combination of direct and indirect estimates of effects to evaluate the roles of HFNC, NIV, and COT in the postextubation period.

\section{Methods}

This study adhered to the Preferred Reporting Items for Systematic Reviews and Meta-analyses extension statement for reporting network meta-analyses (PRISMANMA) (21).

\section{Data sources and searches}

We searched PubMed, Embase, and ClinicalTrials. gov for unpublished and ongoing trials, and conference proceedings up to November 2019 for potentially relevant studies published in English. Reference lists of relevant articles were also reviewed. The inclusion criteria were as follows: (I) study type, RCT; (II) study population, intensive care unit (ICU) adult patients with planned extubation requiring sequential respiratory support in the ICU; and (III) intervention, HFNC vs. NIV, HFNC vs. COT, and NIV vs. COT. The exclusion criteria were as follows: (I) the study was not published in English; (II) the study focused on pediatric patients; (III) data were unavailable; and (IV) duplicate publications.

\section{Study selection and data extraction}

Two authors (LS and LBN) independently screened the citations and abstracts in duplicate and performed data extraction. All references that were judged potentially relevant were evaluated for full-text eligibility. Discrepancies were resolved by consensus with a third author (YML). If relevant data or information was missing, we attempted to contact the authors of the studies.

\section{Outcome measures}

The primary outcome was the reintubation rate. The secondary outcomes were the incidence of post-extubation $\mathrm{ARF}$ and post-extubation hospital-acquired pneumonia (HAP), length of stay (LOS) in the ICU, LOS in the hospital, ICU mortality, and hospital mortality.

\section{Assessment of risk of bias (RoB)}

Two authors (LS and LBN) independently assessed the risk of bias (RoB) of the individual studies using the revised Cochrane risk-of-bias tool for randomized trials (22) and classified the RoB as low or high. In case of disagreement regarding the RoB, the issue was resolved by discussion and consensus with a third author (YML).

\section{Statistical analysis and quality of evidence}

A random effect network meta-analysis was performed using a Bayesian framework, and we calculated mean differences for continuous outcomes and odds ratios (ORs) 


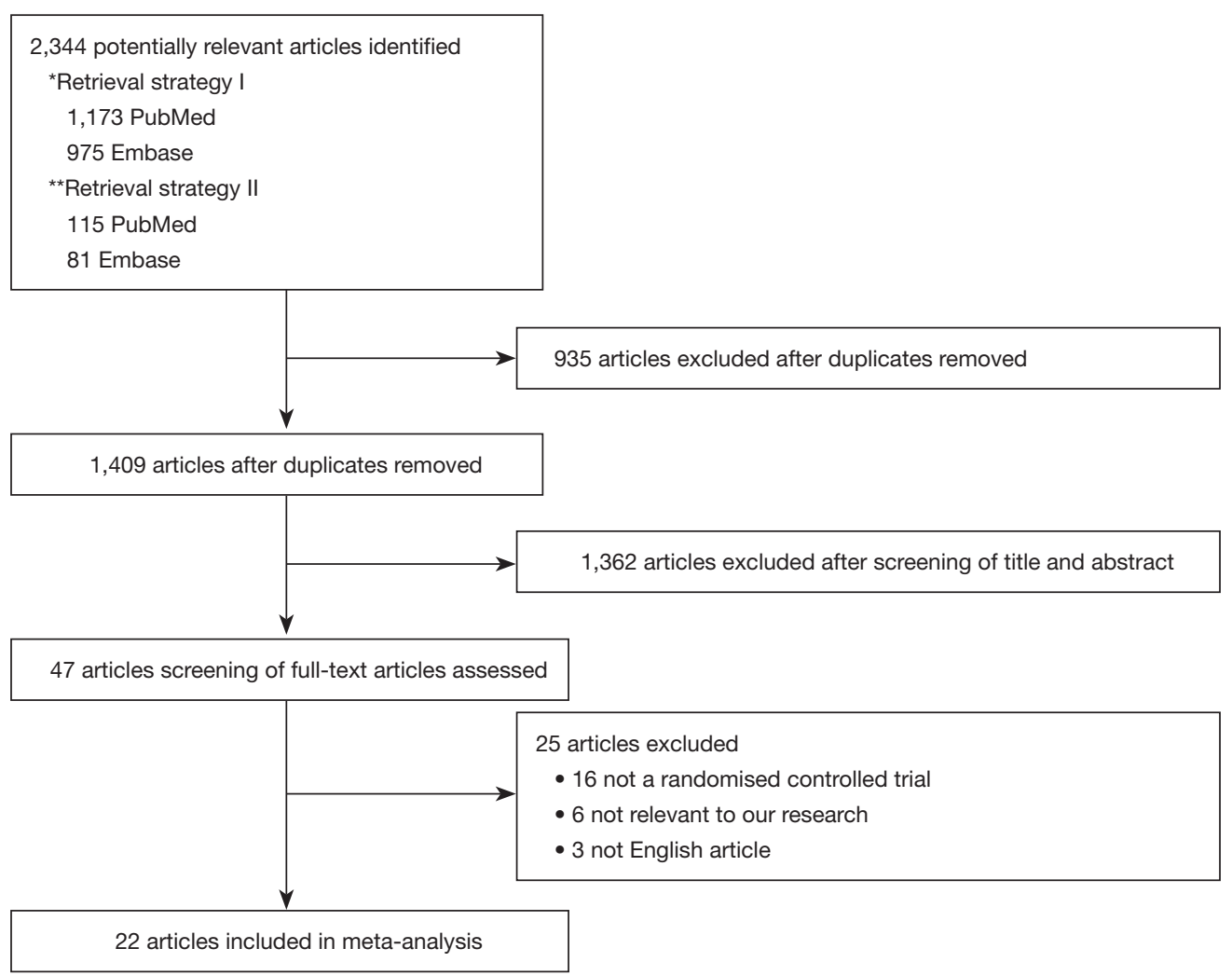

Figure 1 PRISMA flowchart. *Retrieval strategy I: "nippv" or "bipap" or "cpap” or "niv" or "nipsv" or "noninvasive positive pressure ventilation" or "non invasive positive pressure ventilation" or "noninvasive ventilation" or "non invasive ventilation" or "bilevel positive airway pressure" or "continuous positive airway pressure" or "noninvasive pressure support ventilation" or "non invasive pressure support ventilation" or "mask ventilation" or "nasal ventilation") and (airway extubation or ventilator weaning); ** Retrieval strategy II: "high flow nasal cannula" or "high flow nasal therapy" or "high flow nasal oxygen" or "high flow oxygen therapy" or "high flow therapy" or "optiflow (respiration)" or "nasal highflow") and (airway extubation or ventilator weaning).

for dichotomous outcomes. Medians and interquartile ranges were converted to means and standard deviations using a previously published method (23).

The network meta-analysis was performed using the package "gemtc" (version 0.8-2) in R (version 3.4.4, The $\mathrm{R}$ Foundation for Statistical Computing). This package is based on an approach that follows the graph-theoretical methodology. We ranked the treatments using the P-score to represent the degree of certainty that a specific treatment was better than the other treatments. A P-score close to 1 indicated that the treatment was certain to be the best and a score close to 0 indicated that the treatment was certain to be the worst. The value of $\mathrm{I}^{2} \geq 50 \%$ would be considered substantial heterogeneity. Trial sequential analysis (TSA) was conducted with TSA version 0.9 .5 .10 to limit the possibility of type I error.

\section{Results}

\section{Literature search}

We identified 2,344 citations, of which 47 were considered potentially eligible after reviewing the full-text articles. We finally included 22 studies with 4,218 patients (Figure 1).

Of the 22 eligible trials, four compared HFNC with COT, 15 compared NIV with COT, and three compared NIV with HFNC (Table 1). The trial sample sizes ranged from 38 to 830 patients. The RoB was high in 10 trials and low in 12 trials (Figures 2,3).

\section{Clinical outcomes}

\section{Reintubation rate}

Twenty-two eligible articles (4,218 patients) 
Table 1 Characteristics of individual studies included in the network meta-analysis

\begin{tabular}{|c|c|c|c|c|c|}
\hline $\begin{array}{l}\text { Study and } \\
\text { published year }\end{array}$ & Settings & Participants & Interventions & Reintubation rate & Other key outcomes \\
\hline $\begin{array}{l}\text { Jiang et al. (24), } \\
1999\end{array}$ & Single-center ICU & $\mathrm{N}=93$ & COT: N=46; NIV: N=47 & $\begin{array}{c}\text { COT: } 7 \text { (15.20\%); NIV: } \\
13(27.66 \%)\end{array}$ & NA \\
\hline $\begin{array}{l}\text { Keenan et al. (25), } \\
2002\end{array}$ & Single-center ICU & $\mathrm{N}=81$ & COT: N=42; NIV: N=39 & $\begin{array}{c}\text { COT: } 29 \text { (69\%); NIV: } \\
28(72 \%)\end{array}$ & $\begin{array}{l}\text { HAP, ICU-stay, hospital-stay, ICU-mortality, } \\
\text { hospital-mortality }\end{array}$ \\
\hline $\begin{array}{l}\text { Esteban et al. (26), } \\
2004\end{array}$ & 37 ICU centers & $\mathrm{N}=221$ & COT: $N=107 ;$ NIV: $N=114$ & $\begin{array}{c}\text { COT: } 51 \text { (48\%); NIV: } \\
55(48 \%)\end{array}$ & ARF, ICU-stay, ICU-mortality \\
\hline $\begin{array}{l}\text { Kindgen-Milles } \\
\text { et al. (27), } 2005\end{array}$ & $\begin{array}{l}\text { Single-center ICU in } \\
\text { Germany }\end{array}$ & $\mathrm{N}=50$ & COT: N=25; NIV: N=25 & $\begin{array}{c}\text { COT: } 4 \text { (16\%); NIV: } \\
1(4 \%)\end{array}$ & $\begin{array}{l}\text { ARF, HAP, ICU-stay, hospital-stay, } \\
\text { ICU-mortality, hospital-mortality }\end{array}$ \\
\hline $\begin{array}{l}\text { Nava et al. (28), } \\
2005\end{array}$ & 3 ICU centers in Italy & $\mathrm{N}=97$ & СОТ: $N=49 ; \mathrm{NIV}: \mathrm{N}=48$ & $\begin{array}{c}\text { COT: } 12(24 \%) \text {; NIV: } \\
4(8 \%)\end{array}$ & ICU-stay, hospital-stay, ICU-mortality \\
\hline $\begin{array}{l}\text { Ferrer et al. (29), } \\
2009\end{array}$ & 3 ICU centers in Spain & $\mathrm{N}=106$ & СОT: N=52; NIV: N=54 & $\begin{array}{c}\text { COT: } 10 \text { (19.2\%); NIV: } \\
6(11.1 \%)\end{array}$ & $\begin{array}{l}\text { ARF, HAP, ICU-stay, hospital-stay, } \\
\text { ICU-mortality, hospital-mortality }\end{array}$ \\
\hline $\begin{array}{l}\text { Girault et al. (30), } \\
2011\end{array}$ & $\begin{array}{l}13 \text { ICU centers in French, } \\
\text { Tunisian }\end{array}$ & $\mathrm{N}=139$ & СОT: N=70; NIV: N=69 & $\begin{array}{c}\text { COT: } 26(37 \%) \text {; NIV: } \\
22(32 \%)\end{array}$ & $\begin{array}{c}\text { ARF, HAP, ICU-stay, ICU-mortality, hospital- } \\
\text { mortality }\end{array}$ \\
\hline $\begin{array}{l}\text { Khilnani et al. (31), } \\
2011\end{array}$ & Single-center ICU in India & $\mathrm{N}=40$ & COT: N=20; NIV: N=20 & $\begin{array}{c}\text { COT: } 5 \text { (25\%); NIV: } \\
3(15 \%)\end{array}$ & ICU-stay, hospital-stay \\
\hline $\begin{array}{l}\text { Cekmen et al. (32), } \\
2011\end{array}$ & Single-center ICU in Turkey & $\mathrm{N}=40$ & СОT: N=20; NIV: N=20 & $\begin{array}{c}\text { COT: } 5 \text { (25\%); NIV: } \\
3(15 \%)\end{array}$ & NA \\
\hline $\begin{array}{l}\text { Su et al. (33), } \\
2012\end{array}$ & $\begin{array}{c}3 \text { ICU centers in Taiwan, } \\
\text { China }\end{array}$ & $N=406$ & COT: $N=204 ;$ NIV: N=202 & $\begin{array}{c}\text { COT: } 16(7.7 \%) ; \text { NIV: } \\
21(10.4 \%)\end{array}$ & ARF, ICU-mortality \\
\hline $\begin{array}{l}\text { Al Jaaly et al. (34), } \\
2013\end{array}$ & $\begin{array}{l}\text { Single-center ICU in } \\
\text { England }\end{array}$ & $\mathrm{N}=126$ & СОT: N=63; NIV: N=63 & $\begin{array}{c}\text { COT: } 2(3.2 \%) ; \text { NIV: } \\
1(1.6 \%)\end{array}$ & $\begin{array}{l}\text { ARF, HAP, ICU-stay, hospital-stay, } \\
\text { ICU-mortality, hospital-mortality }\end{array}$ \\
\hline $\begin{array}{l}\text { Mohamed } \\
\text { et al. (35), } 2013\end{array}$ & $\begin{array}{c}\text { Single-center ICU in Saudi } \\
\text { Arabia }\end{array}$ & $\mathrm{N}=120$ & СОт: N=60; NIV: N=60 & $\begin{array}{c}\text { COT: } 15(25 \%) \text {; NIV: } \\
9(15 \%)\end{array}$ & ICU-stay, ICU-mortality \\
\hline $\begin{array}{l}\text { Ornico et al. (36), } \\
2013\end{array}$ & Single-center ICU in Brazil & $\mathrm{N}=38$ & СОТ: $N=18 ;$ NIV: N=20 & $\begin{array}{c}\text { COT: } 7 \text { (39\%); NIV: } \\
1(5 \%)\end{array}$ & ICU-stay, hospital-mortality \\
\hline $\begin{array}{l}\text { Maggiore } \\
\text { et al. (15), } 2014\end{array}$ & 2 ICU centers in Italy & $\mathrm{N}=105$ & COT: N=52; HFNC: N=53 & $\begin{array}{c}\text { COT: } 16(30.8 \%) ; \text { HFNC: } \\
6(11.3 \%)\end{array}$ & ARF, ICU-stay, hospital-mortality \\
\hline $\begin{array}{l}\text { Stéphan et al. (18), } \\
2015\end{array}$ & 6 ICU centers in France & $N=830$ & HFNC: $N=414 ;$ NIV: $N=416$ & $\begin{array}{l}\text { HFNC: } 87(21 \%) \text {; NIV: } \\
91(21.8 \%)\end{array}$ & $\begin{array}{l}\text { ARF, HAP, ICU-stay, hospital-stay, } \\
\text { ICU-mortality }\end{array}$ \\
\hline $\begin{array}{l}\text { Hernández } \\
\text { et al. (19), } 2016\end{array}$ & 3 ICU centers in Spain & $\mathrm{N}=604$ & HFNC: $N=290 ; N I V: ~ N=314$ & $\begin{array}{c}\text { HFNC: } 66(22.8 \%) \text {; NIV: } \\
60(19.1 \%)\end{array}$ & $\begin{array}{l}\text { ARF, HAP, ICU-stay, hospital-stay, } \\
\text { ICU-mortality, hospital-mortality }\end{array}$ \\
\hline $\begin{array}{l}\text { Futier et al. (37), } \\
2016\end{array}$ & $3 \mathrm{ICU}$ centers in France & $\mathrm{N}=220$ & $\begin{array}{l}\text { COT: } N=112 ; \text { HFNC: } \\
\qquad N=108\end{array}$ & $\begin{array}{c}\text { СОT: } 7 \text { (6.3\%); HFNC: } \\
4(3.7 \%)\end{array}$ & $\begin{array}{c}\text { ARF, HAP, ICU-stay, hospital-stay, hospital- } \\
\text { mortality }\end{array}$ \\
\hline $\begin{array}{l}\text { Hernández } \\
\text { et al. (16), } 2016\end{array}$ & $7 \mathrm{ICU}$ centers in Spain & $N=527$ & $\begin{array}{l}\text { COT: } N=263 \text {; HFNC: } \\
\qquad N=264\end{array}$ & $\begin{array}{c}\text { COT: } 32 \text { (12.2\%); HFNC: } \\
13(4.9 \%)\end{array}$ & $\begin{array}{l}\text { ARF, HAP, ICU-stay, hospital-stay, } \\
\text { ICU-mortality, hospital-mortality }\end{array}$ \\
\hline $\begin{array}{l}\text { Song et al. (38), } \\
2017\end{array}$ & Single-center ICU in China & $\mathrm{N}=60$ & COT: $N=30 ;$ HFNC: $N=30$ & $\begin{array}{c}\text { COT: } 3 \text { (10\%); HFNC: } \\
1(3.3 \%)\end{array}$ & NA \\
\hline $\begin{array}{l}\text { Vargas et al. (39), } \\
2017\end{array}$ & $6 \mathrm{ICU}$ centers in France & $N=144$ & СОТ: N=72; NIV: N=71 & $\begin{array}{c}\text { COT: } 13(18.1 \%) \text {; NIV: } \\
6(8.5 \%)\end{array}$ & ARF, ICU-stay, ICU-mortality \\
\hline $\begin{array}{l}\text { Vaschetto } \\
\text { et al. (40), } 2019\end{array}$ & $\begin{array}{l}9 \text { ICU centers in China, } \\
\text { Italy }\end{array}$ & $N=130$ & COT: $N=65 ;$ NIV: N=65 & $\begin{aligned} \text { COT: } & 7(10.7 \%) ; \text { NIV: } \\
& 3(4.6 \%)\end{aligned}$ & $\begin{array}{l}\text { ARF, HAP, ICU-stay, hospital-stay, } \\
\text { ICU-mortality, hospital-mortality }\end{array}$ \\
\hline $\begin{array}{l}\text { Jing et al. (41), } \\
2019\end{array}$ & Single-center ICU in China & $\mathrm{N}=42$ & HFNC: $N=22 ; N I V: N=20$ & $\begin{array}{c}\text { HFNC: } 2 \text { (9.0\%); NIV: } \\
1(5.0 \%)\end{array}$ & ARF, ICU-stay, hospital-mortality \\
\hline
\end{tabular}

HAP, hospital-acquired pneumonia; ARF, acute respiratory failure; ICU, intensive care unit; NIV, noninvasive ventilation; COT, conventional oxygen therapy; HFNC, high-flow nasal cannula. 


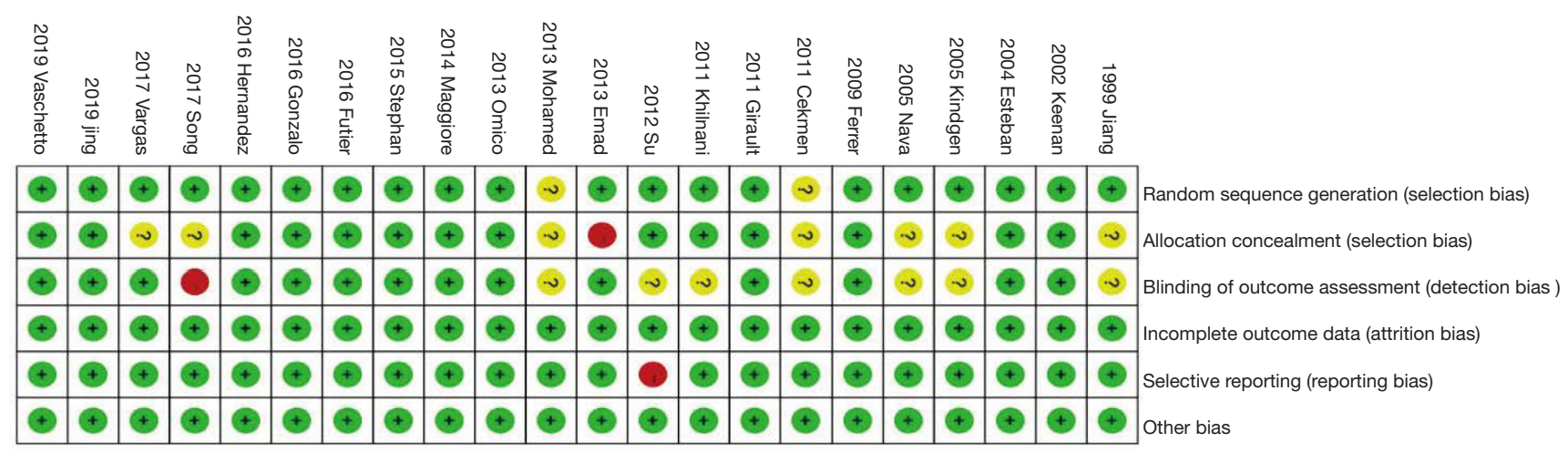

Figure 2 RoB in eligible studies. RoB, risk of bias.

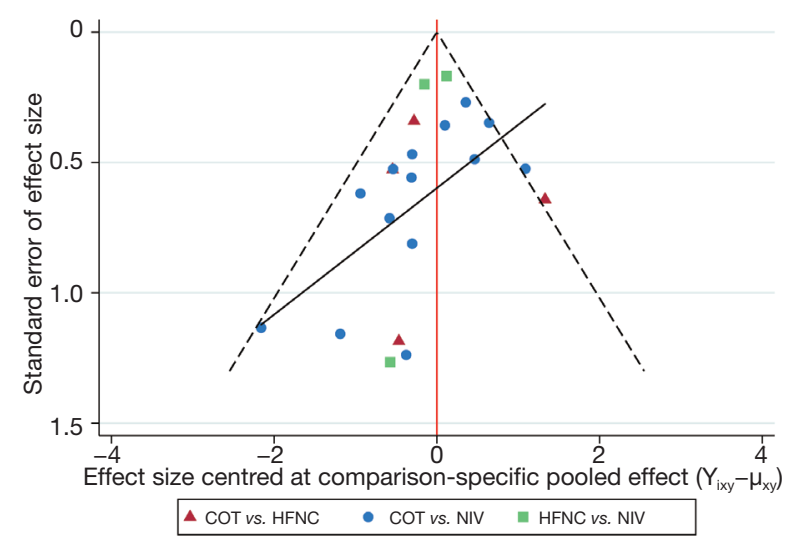

Figure 3 Funnel plot of association between estimated effect size for each study. NIV, noninvasive ventilation; COT, conventional oxygen therapy; HFNC, high-flow nasal cannula.

$(15,16,18,19,24-41)$ reported the reintubation rate. The network geometry is shown in Figure 4. Extubated patients who were supported with NIV had a significantly lower incidence of reintubation than patients who were supported with COT [OR: 0.63 , 95\% confidence interval (CI): 0.42, 0.89] (Figure 5). However, there was no significant difference in the reintubation rate between HFNC and NIV (OR: 1.05, 95\% CI: 0.60, 1.81) (Figure 5). Bayesian analysis identified COT as the worst respiratory support method for potentially increasing the incidence of reintubation, while NIV was ranked second and HFNC as third worst among these three strategies. There was no significant difference in reintubation between NIV and HFNC, and between HFNC and COT in pooled estimates in the network metaanalysis (Table 2, Figure 6). Among the 22 included articles, four (983 patients) $(19,28,30,39)$ focused on patients at

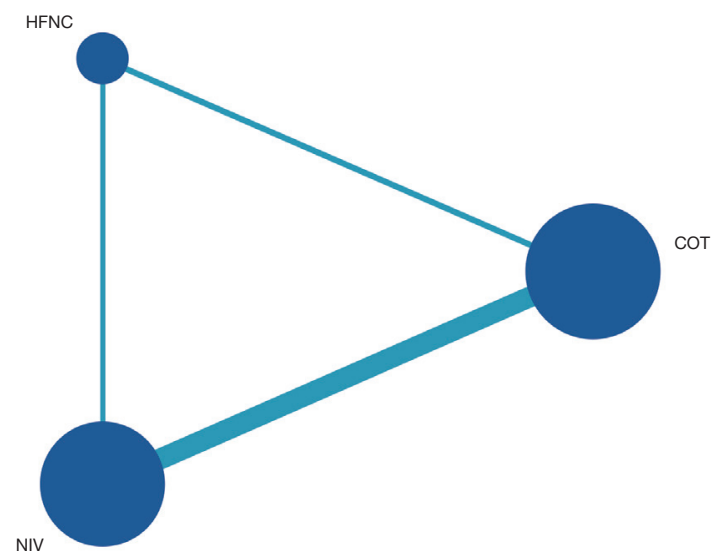

Figure 4 Network of comparisons for Bayesian network meta-analysis. The size of the nodes is proportional to the number of patients (in parentheses) randomized to receive the treatment. The width of the lines is proportional to the number of trials (beside the line) comparing the connected treatments. NIV, noninvasive ventilation; COT, conventional oxygen therapy; HFNC, high-flow nasal cannula.

high risk for reintubation. The network meta-analysis in this subpopulation showed no significant difference in the risk for reintubation among the three strategies (HFNC vs. COT: OR: 0.63, 95\% CI: 0.11, 3.1; NIV vs. COT: OR: $0.49,95 \%$ CI: $0.18,1.2$; NIV vs. HFNC: OR: 0.80 , 95\% CI: 0.19, 3.2) (Figure 5).

\section{Secondary outcomes}

We divided the included trials into low- and high-bias studies. Analysis of 12 low-bias trials (3,043 patients) $(15,16,18,19,25,26,29,30,36,37,40,41)$ showed that patients who were supported with NIV had a significantly lower 


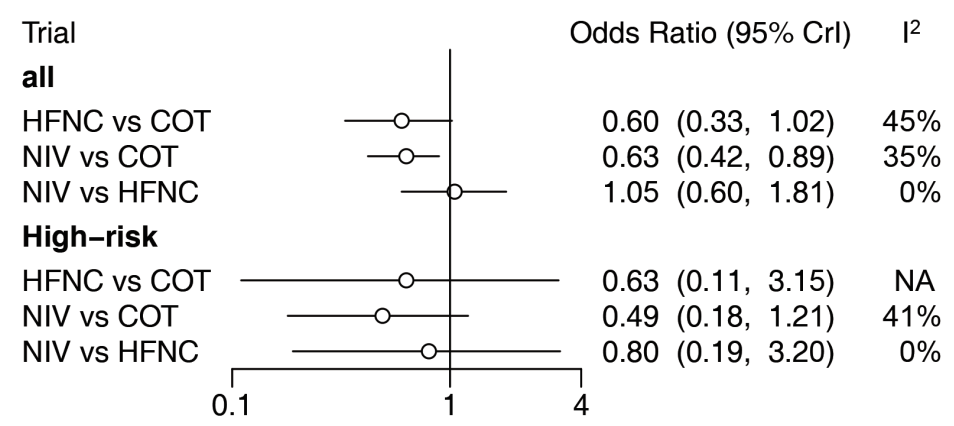

Figure 5 Forest plot of included trials and trials focusing on high-risk patients. High-risk patients for reintubation were defined as patients who fulfilled at least one of the following criteria: (I) age $>65$ years; (II) APACHE II score $>12$ on the extubation day; (III) inability to cope with respiratory secretions; (IV) patients with difficult weaning or prolonged MV made the first attempt to disconnect the ventilator; (V) two or more comorbidities; (VI) heart failure as the main indication for MV; (VII) moderate to severe chronic obstructive pulmonary disease; (VIII) airway patency problems, including a high risk of developing throat edema; and (IX) MV for >7 days. MV, mechanical ventilation; NIV, noninvasive ventilation; COT, conventional oxygen therapy; HFNC, high-flow nasal cannula; CI, confidence interval.

Table 2 Pooled estimates of the network meta-analysis

\begin{tabular}{lccc}
\hline Relative effects & COT & HFNC & NIV \\
\hline COT & - & $0.60(0.33,1.02)$ & $0.63(0.42,0.89)$ \\
HFNC & $1.66(0.98,3.02)$ & - & $1.05(0.60,1.81)$ \\
NIV & $0.95(0.55,1.67)$ & $1.58(1.13,2.40)$ & - \\
\hline
\end{tabular}

Results are ORs in the column-defining treatment compared with ORs in the row-defining treatment. For efficacy, ORs $>1$ favored the column-defining treatment. OR, odds ratio; NIV, noninvasive ventilation; COT, conventional oxygen therapy; HFNC, high-flow nasal cannula.

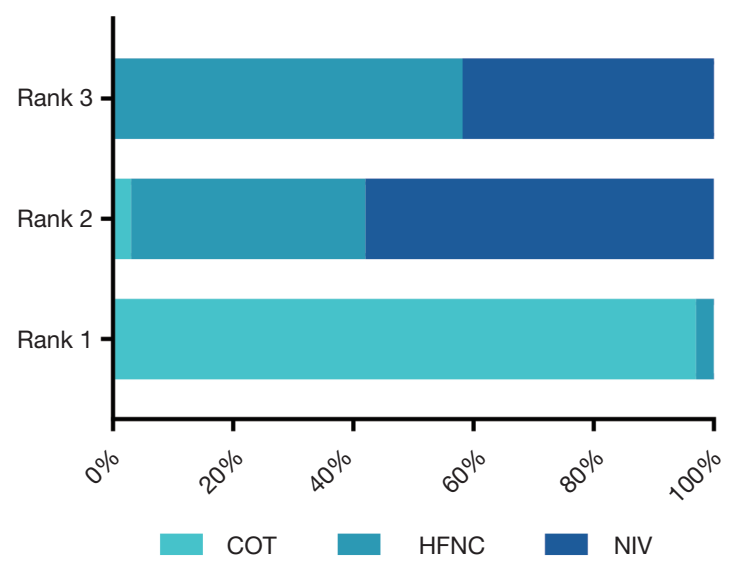

Figure 6 Ranking of treatments in terms of reintubation. NIV, noninvasive ventilation; COT, conventional oxygen therapy; HFNC, high-flow nasal cannula.

incidence of reintubation than patients who were supported with COT. However, there was no significant difference in the reintubation rate between NIV and HFNC, and between HFNC and COT. However, 10 trials with high bias $(24,27,28,31-35,38,39)$ showed no benefit of HFNC or NIV for reducing the reintubation rate compared with COT, and there was no significant difference in the reintubation rate between HFNC and NIV (Figure 7).

We also carried out subgroup analysis according to receiving surgery. Of the 22 included trials, four $(1,226$ patients) $(18,27,34,37)$ focused on surgery patients and the other 18 (2,992 patients) (15,16,19,24-26,28$33,35,36,38-41)$ focused on non-surgery patients. There was no significant difference in the reintubation rate in the surgery subgroup among the three strategies. However, HFNC or NIV reduced the reintubation rate compared with COT among the non-surgery subgroup, and there was no significant difference between NIV and HFNC (Figure 8). Of the 22 eligible trials, 10 (2,813 patients) $(16,18,19,25,27,29,30,34,37,41)$ reported the incidence of post-extubation HAP. HFNC and NIV reduced the incidence of HAP compared with COT, with no significant difference between 


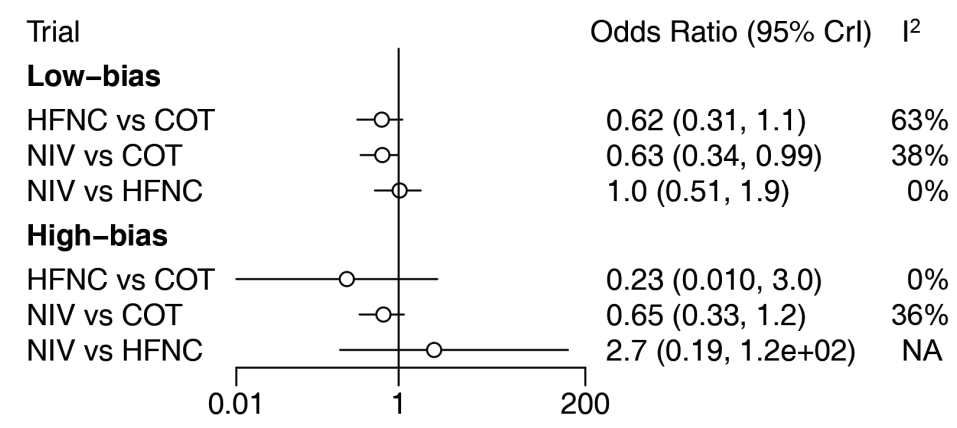

Figure 7 Forest plot for low-bias and high-bias trials. NIV, noninvasive ventilation; COT, conventional oxygen therapy; HFNC, high-flow nasal cannula; CI, confidence interval.

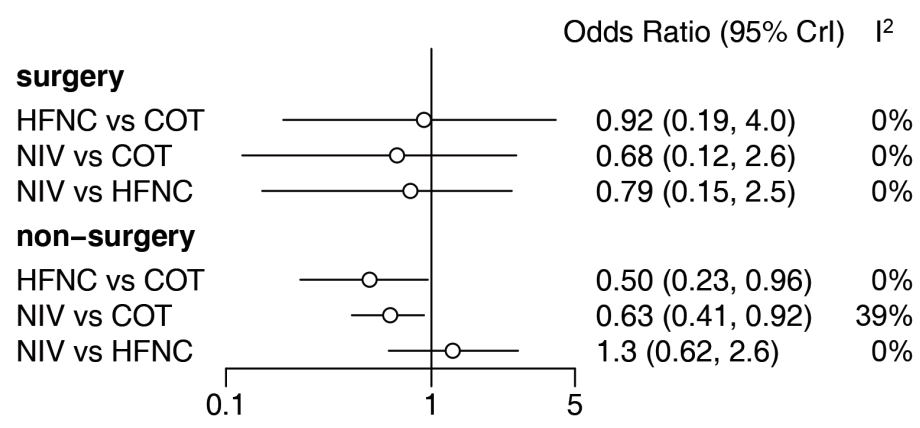

Figure 8 Forest plot for surgery and non-surgery subgroups. NIV, noninvasive ventilation; COT, conventional oxygen therapy; HFNC, high-flow nasal cannula; CI, confidence interval.

NIV and HFNC (Figure 9). Fourteen trials $(3,649$ patients) $(15,16,18,19,26,27,29,30,33,34,37,39-41)$ reported the incidence of post-extubation ARF, and we found that HFNC or NIV reduced the incidence of ARF compared with COT, with no significant difference between NIV and HFNC (Figure 9). A total of 14 trials (3,580 patients) $(16,18,19,25-30,33-35,39,41)$ reported ICU mortality and 12 (2,168 patients) (15,16,19,25,27,29,30,3 $4,36,37,40,41)$ reported hospital mortality. There was no significant difference in either form of mortality among the three strategies (Figure 9). Eighteen trials (3,619 patients) $(15,16,18,19,25-31,34-37,39-41)$ reported ICU LOS and 11 (2,811 patients) $(16,18,19,25,27-29,31,34,37,41)$ reported hospital LOS. Similarly, there was no significant difference in these LOSs among the three strategies (Figure 10).

\section{Trial sequential analysis}

TSA showed that conventional and O'Brien-Fleming significance boundaries were not crossed by the cumulative
Z-curve. This analysis established that the evidence was not sufficient and conclusive, and thus indicated that further trials were required. Graphic presentation of this analysis is shown in Figure 11.

\section{Discussion}

This network meta-analysis compared three post-extubation respiratory support methods (HFNC, NIV, and COT) in 22 RCTs (4,218 patients). NIV reduced the reintubation rate compared with COT overall and in low bias trials. However, neither HFNC nor NIV showed any benefit in terms of preventing reintubation in high-risk patients and surgery patients. Additionally, HFNC and NIV had similar effects on reducing the incidence of post-extubation ARF and HAP compared with COT. None of the strategies decreased ICU or hospital mortality or shortened the ICU or hospital LOS. However, our research was unable to draw a conclusion regarding the superiority of HFNC or NIV in terms of all of the clinical outcomes. 
HAP

HFNC vs COT NIV vs COT NIV vs HFNC

ARF

HFNC vs COT NIV vs COT NIV vs HFNC

ICU-mortality HFNC vs COT NIV vs COT

NIV vs HFNC Hospital-mortality HFNC vs COT NIV vs COT NIV vs HFNC

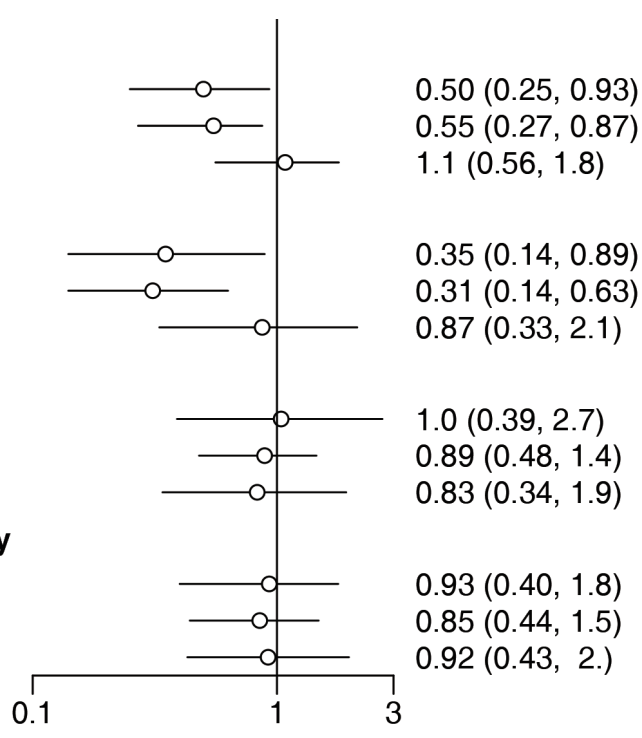

Figure 9 Forest plot for the secondary outcome. HAP, hospital-acquired pneumonia; ARF, acute respiratory failure; ICU, intensive care unit; NIV, noninvasive ventilation; COT, conventional oxygen therapy; HFNC, high-flow nasal cannula; CI, confidence interval.

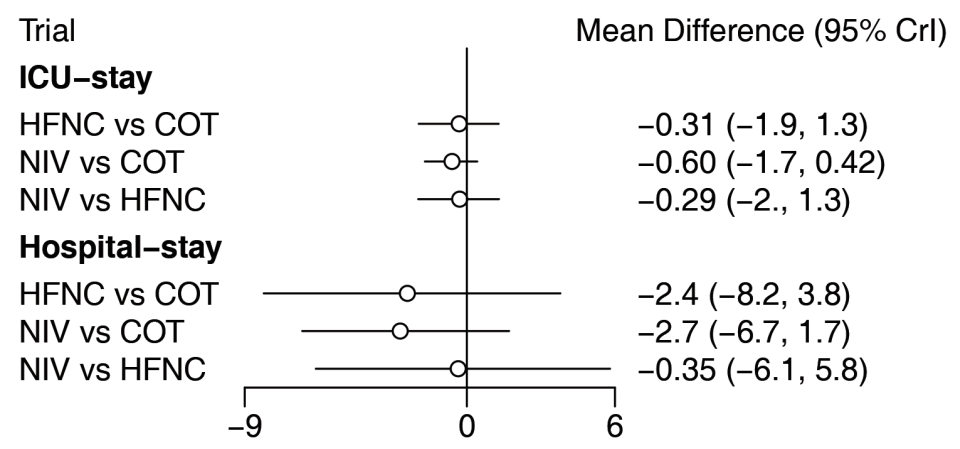

Figure 10 Forest plot for ICU and hospital LOS. ICU, intensive care unit; LOS, length of stay; NIV, noninvasive ventilation; COT, conventional oxygen therapy; HFNC, high-flow nasal cannula; CI, confidence interval.

ICU clinicians must wean and extubate patients as expeditiously as possible. Failure to wean patients from MV is often characterized by an imbalance between respiratory muscle capacity and the respiratory load confronted by those muscles. This imbalance might be caused by factors, such as increased breathing work, the effects of intrinsic positive end-expiratory pressure, and abnormal gas exchange. NIV reduces the work of breathing, provides respiratory muscle unloading, improves alveolar ventilation, and increases oxygenation. Therefore, preventive NIV can theoretically benefit extubated patients (42). However, interestingly, a recent international survey showed significant variation in the use of NIV for weaning and peri-extubation across regions (43). This finding suggests that only some physicians consider NIV to be effective during the post-extubation period. However, HFNC, which has been proposed for adult ARF (44), is widely used for post-extubation respiratory support. However, the results of a recent survey showed that less than half of all physicians, both senior and junior, considered that HFNC would benefit extubated patients (17). The current analysis showed that NIV and HFNC should be used for post-extubation respiratory support, and that HFNC was significantly better tolerated than NIV (45). However, in our study, only NIV benefited extubated patients and there was insufficient evidence to prove that HFNC is good 


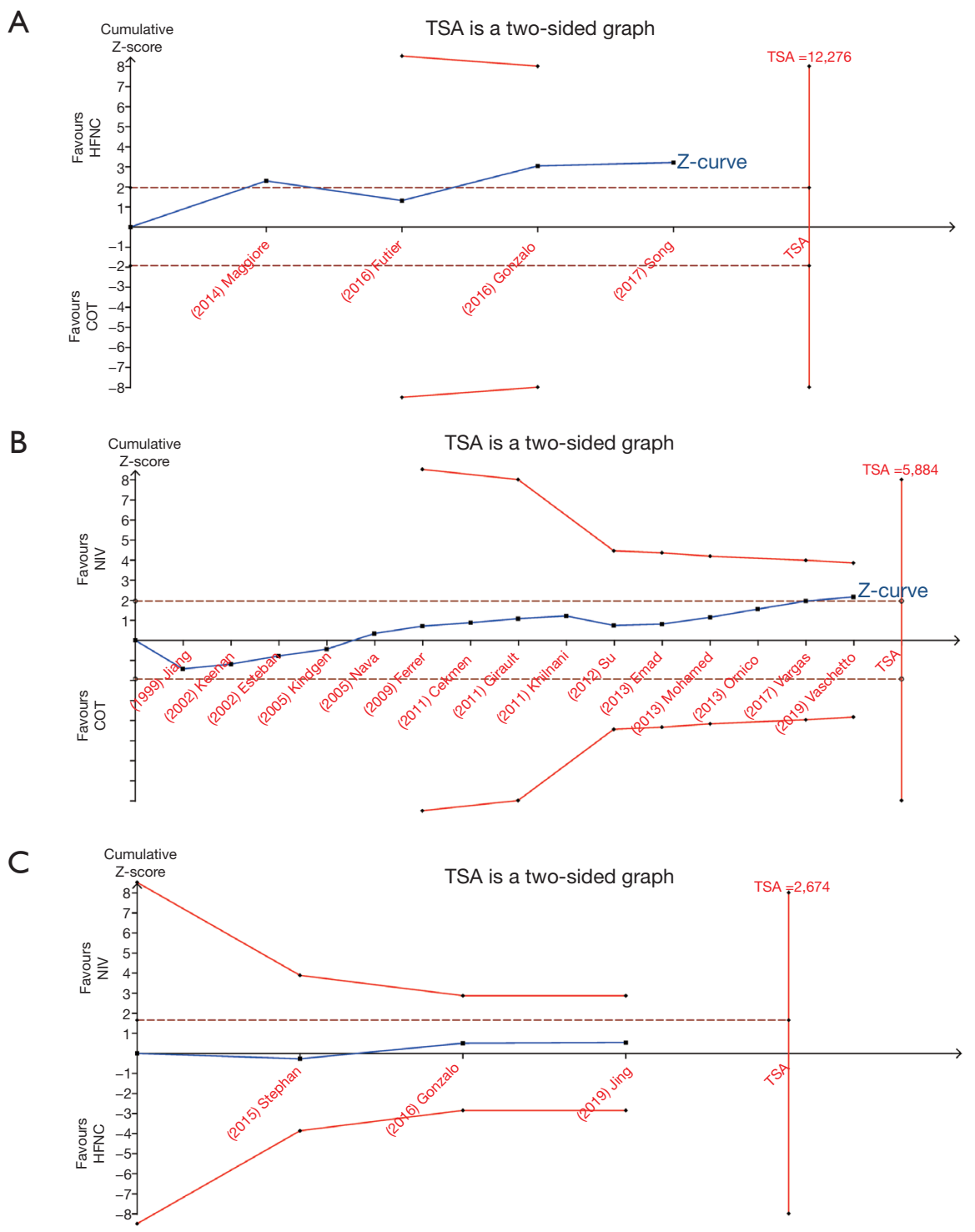

Figure 11 Plot of TSA for the effect of HFNC, COT, and NIV for preventing reintubation. (A) TSA for HFNC vs. COT; (B) TSA for NIV vs. COT; and (C) TSA for NIV vs. HFNC. TSA, trial sequential analysis; NIV, noninvasive ventilation; COT, conventional oxygen therapy; HFNC, high-flow nasal cannula.

for patients. Therefore, HFNC requires further study. Furthermore, HFNC was not mentioned in the ATS/ACCP clinical practice guidelines for weaning (4). We consider that HFNC is probably more useful for acute hypoxemic respiratory failure than hypercapnic respiratory failure and the reverse is probably true for NIV. However, our study did not have sufficient data to prove this possibility.

Surprisingly, we found that HFNC and NIV failed to reduce the reintubation rate compared with COT in high-risk patients. This finding is in contrast to two previous meta-analyses, including general and high-risk patients, which concluded that early use of NIV decreased the reintubation rate. However, patients at high-risk of reintubation only accounted for $35 \%$ of the total weight in the meta-analyses in these studies, and the ORs and 95\% CIs in both meta-analyses were not significant $(5,46)$. The current study evaluated the efficacies of HFNC and NIV in reducing the reintubation rate compared with COT in high-risk patients using data from four articles (983 patients) $(19,28,32,41)$. Only one study with a relatively 
small sample size showed that NIV was more effective than COT (28). Two studies could not preclude the possibility that such patients could benefit from NIV compared with COT $(30,39)$, and a large study showed that HFNC was not inferior to NIV for preventing reintubation (19). However, these studies showed that NIV may improve weaning results in these patients by reducing the risk of post-extubation ARF. From this point of view, HFNC could also be used in such a population.

Our study showed that the efficacy of HFNC and NIV in reducing the reintubation rate was most obvious in nonsurgery patients. Although Nava et al. provided a moderate level of evidence (grade 2) to support the use of NIV for postoperative ARF (47), other studies showed that it failed in approximately $20 \%$ of patients after cardiothoracic surgery $(48,49)$. This could be explained by the fact that two eligible trials $(27,34)$ in patients who had surgery compared NIV with COT and one compared HFNC with NIV (18), but no trial directly compared HFNC with COT.

Finally, we found that NIV decreased the reintubation rate in the general ICU population, but they both (NIV and HFNC) decrease HAP and post-extubation ARF. However, our study failed to show that HFNC and NIV could improve other clinical outcomes, such as ICU and hospital mortality, and ICU and hospital LOS. Furthermore, because both HFNC and NIV had similar effects in this study, the effect of combining these two methods may be of interest. A recent multicenter RCT addressed this issue (50). This trial showed that HFNC plus NIV applied immediately after extubation significantly decreased the risks of reintubation and post-extubation ARF in patients with $M V$ at high risk of extubation failure compared with HFNC alone. This result might provide further insight into selection of post-extubation respiratory support methods.

Although this is the first network meta-analysis on this issue and the first to study heterogeneous populations of critically ill patients, there are several limitations of this study. First, we limited the included studies to full-text English publications because we assumed that non-English reports would not provide sufficient methodological or outcome data. Second, among 22 eligible trials, only four compared HFNC with COT and three compared HFNC with NIV. There were relatively few studies on HFNC compared with NIV, which may have caused overestimation of the intervention effect, and the quality of evidence should possibly be rated down. Third, we did not include the duration of NIV, HFNC, conventional oxygen, and this would have caused bias. Finally, limited statistical power was present in evaluation of the outcome, and this was confirmed through TSA. This limited statistical power needs to be taken into account in the overall scientific interpretation.

\section{Conclusions}

NIV reduces the reintubation rate in adult patients undergoing planned extubation compared with COT and HFNC. Further research is required to evaluate the benefits of the combination of NIV plus HFNC.

\section{Acknowledgments}

Funding: The study was funded by the National Science and Technology Major Project (No. 2017ZX10204401), National Natural Science Foundation of China (81970071 and 81870069) and the Natural Science Foundation of Guangdong Province, China (No. 2020A1515011459).

\section{Footnote}

Conflicts of Interest: All authors have completed the ICMJE uniform disclosure form (available at http://dx.doi. org/10.21037/jtd-20-1050). The authors have no conflicts of interest to declare.

Ethical Statement: The authors are accountable for all aspects of the work in ensuring that questions related to the accuracy or integrity of any part of the work are appropriately investigated and resolved.

Open Access Statement: This is an Open Access article distributed in accordance with the Creative Commons Attribution-NonCommercial-NoDerivs 4.0 International License (CC BY-NC-ND 4.0), which permits the noncommercial replication and distribution of the article with the strict proviso that no changes or edits are made and the original work is properly cited (including links to both the formal publication through the relevant DOI and the license). See: https://creativecommons.org/licenses/by-nc-nd/4.0/.

\section{References}

1. Coplin WM, Pierson DJ, Cooley KD, et al. Implications of extubation delay in brain-injured patients meeting standard weaning criteria. Am J Respir Crit Care Med 2000;161:1530-6. 
2. Thille AW, Harrois A, Schortgen F, et al. Outcomes of extubation failure in medical intensive care unit patients. Crit Care Med 2011;39:2612-8.

3. Epstein SK, Ciubotaru RL, Wong JB. Effect of failed extubation on the outcome of mechanical ventilation. Chest 1997;112:186-92.

4. Fan E, Zakhary B, Amaral A, et al. Liberation from mechanical ventilation in critically ill adults. An official ATS/ACCP clinical practice guideline. Ann Am Thorac Soc 2017;14:441-3.

5. Glossop AJ, Shephard N, Bryden DC, et al. Noninvasive ventilation for weaning, avoiding reintubation after extubation and in the postoperative period: a metaanalysis. Br J Anaesth 2012;109:305-14.

6. Antro C, Merico F, Urbino R, et al. Non-invasive ventilation as a first-line treatment for acute respiratory failure: "real life" experience in the emergency department. Emerg Med J 2005;22:772-7.

7. Hess DR. Noninvasive ventilation for acute respiratory failure. Respir Care 2013;58:950-72.

8. Ozyilmaz E, Ugurlu AO, Nava S. Timing of noninvasive ventilation failure: causes, risk factors, and potential remedies. BMC Pulm Med 2014;14:19.

9. Liu J, Duan J, Bai L, et al. Noninvasive ventilation intolerance: characteristics, predictors, and outcomes. Respir Care 2016;61:277-84.

10. Groves N, Tobin A. High flow nasal oxygen generates positive airway pressure in adult volunteers. Aust Crit Care 2007;20:126-31.

11. Corley A, Caruana LR, Barnett AG, et al. Oxygen delivery through high-flow nasal cannulae increase end-expiratory lung volume and reduce respiratory rate in post-cardiac surgical patients. Br J Anaesth 2011;107:998-1004.

12. Chanques G, Riboulet F, Molinari N, et al. Comparison of three high flow oxygen therapy delivery devices: a clinical physiological cross-over study. Minerva Anestesiol 2013;79:1344-55.

13. Idone FA, Festa R, Antonicelli F, et al. Nasal high-flow oxygen therapy vs. standard oxygen therapy via venturi mask after extubation: preliminary results of a randomized, controlled trial. Intensive Care Medicine 2010;36:S112.

14. Manley BJ, Owen LS, Doyle LW, et al. High-flow nasal cannulae in very preterm infants after extubation. New Engl J Med 2013;369:1425-33.

15. Maggiore SM, Idone FA, Vaschetto R, et al. Nasal highflow versus Venturi mask oxygen therapy after extubation. Effects on oxygenation, comfort, and clinical outcome. Am J Respir Crit Care Med 2014;190:282-8.
16. Hernández G, Vaquero C, González P, et al. Effect of postextubation high-flow nasal cannula vs conventional oxygen therapy on reintubation in low-risk patients: a randomized clinical trial. JAMA 2016;315:1354-61.

17. Besnier E, Hobeika S, NSeir S, et al. High-flow nasal cannula therapy: clinical practice in intensive care units. Ann Intensive Care 2019;9:98.

18. Stéphan F, Barrucand B, Petit P, et al. High-flow nasal oxygen vs noninvasive positive airway pressure in hypoxemic patients after cardiothoracic surgery: a randomized clinical trial. JAMA 2015;313:2331-9.

19. Hernández G, Vaquero C, Colinas L, et al. Effect of postextubation high-flow nasal cannula vs noninvasive ventilation on reintubation and postextubation respiratory failure in high-risk patients: a randomized clinical trial. JAMA 2016;316:1565-74.

20. Yoo JW, Synn A, Huh JW, et al. Clinical efficacy of highflow nasal cannula compared to noninvasive ventilation in patients with post-extubation respiratory failure. Korean J Intern Med 2016;31:82-8.

21. Hutton B, Salanti G, Caldwell DM, et al. The PRISMA extension statement for reporting of systematic reviews incorporating network meta-analyses of health care interventions: checklist and explanations. Ann Intern Med 2015;162:777-84.

22. Chandler J, Clarke M, McKenzie J, et al. Cochrane Methods. Cochrane Database of Systematic Reviews 2016. doi: 10.1002/14651858.CD201601.

23. Hozo SP, Djulbegovic B, Hozo I. Estimating the mean and variance from the median, range, and the size of a sample. BMC Med Res Methodol 2005;5:13.

24. Jiang JS, Kao SJ, Wang SN. Effect of early application of biphasic positive airway pressure on the outcome of extubation in ventilator weaning. Respirology 1999;4:161-5.

25. Keenan SP, Powers C, McCormack DG, et al. Noninvasive positive-pressure ventilation for postextubation respiratory distress: a randomized controlled trial. JAMA 2002;287:3238-44.

26. Esteban A, Frutos-Vivar F, Ferguson ND, et al. Noninvasive positive-pressure ventilation for respiratory failure after extubation. N Engl J Med 2004;350:2452-60.

27. Kindgen-Milles D, Müller E, Buhl R, et al. Nasalcontinuous positive airway pressure reduces pulmonary morbidity and length of hospital stay following thoracoabdominal aortic surgery. Chest 2005;128:821-8.

28. Nava S, Gregoretti C, Fanfulla F, et al. Noninvasive ventilation to prevent respiratory failure after extubation in high-risk patients. Crit Care Med 2005;33:2465-70. 
29. Ferrer M, Sellares J, Valencia M, et al. Non-invasive ventilation after extubation in hypercapnic patients with chronic respiratory disorders: randomised controlled trial. Lancet 2009;374:1082-8.

30. Girault C, Bubenheim M, Abroug F, et al. Noninvasive ventilation and weaning in patients with chronic hypercapnic respiratory failure: a randomized multicenter trial. Am J Respir Crit Care Med 2011;184:672-9.

31. Khilnani GC, Galle AD, Hadda V, et al. Non-invasive ventilation after extubation in patients with chronic obstructive airways disease: a randomised controlled trial. Anaesth Intensive Care 2011;39:217-23.

32. Cekmen N, Erdemli O. The comparison of the effects of T-piece and CPAP on hemodynamic parameters, arterial blood gases and success of weaning. Bratisl Lek Listy 2011;112:512-6.

33. Su CL, Chiang LL, Yang SH, et al. Preventive use of noninvasive ventilation after extubation: a prospective, multicenter randomized controlled trial. Respir Care 2012;57:204-10.

34. Al Jaaly E, Fiorentino F, Reeves BC, et al. Effect of adding postoperative noninvasive ventilation to usual care to prevent pulmonary complications in patients undergoing coronary artery bypass grafting: a randomized controlled trial. J Thorac Cardiovasc Surg 2013;146:912-8.

35. Mohamed KAE, Abdalla MH. Role of non invasive ventilation in limiting re-intubation after planned extubation. Egyptian Journal of Chest Diseases and Tuberculosis 2013;62:669-74.

36. Ornico SR, Lobo SM, Sanches HS, et al. Noninvasive ventilation immediately after extubation improves weaning outcome after acute respiratory failure: a randomized controlled trial. Crit Care 2013;17:R39.

37. Futier E, Paugam-Burtz C, Godet T, et al. Effect of early postextubation high-flow nasal cannula vs conventional oxygen therapy on hypoxaemia in patients after major abdominal surgery: a French multicentre randomised controlled trial (OPERA). Intensive Care Med 2016;42:1888-98.

38. Song HZ, Gu JX, Xiu HQ, et al. The value of highflow nasal cannula oxygen therapy after extubation in patients with acute respiratory failure. Clinics (Sao Paulo) 2017;72:562-7.

39. Vargas F, Clavel M, Sanchez-Verlan P, et al. Intermittent noninvasive ventilation after extubation in patients with chronic respiratory disorders: a multicenter randomized controlled trial (VHYPER). Intensive Care Med 2017;43:1626-36.

40. Vaschetto R, Longhini F, Persona P, et al. Early extubation followed by immediate noninvasive ventilation vs. standard extubation in hypoxemic patients: a randomized clinical trial. Intensive Care Med 2019;45:62-71.

41. Jing G, Li J, Hao D, et al. Comparison of high flow nasal cannula with noninvasive ventilation in chronic obstructive pulmonary disease patients with hypercapnia in preventing postextubation respiratory failure: A pilot randomized controlled trial. Res Nurs Health 2019;42:217-25.

42. Epstein SK. Use of noninvasive ventilation to facilitate weaning from mechanical ventilation. In: Esquinas AM. Noninvasive mechanical ventilation and difficult weaning in critical care. Cham: Springer, 2016:165-71.

43. Burns KEA, Raptis S, Nisenbaum R, et al. International practice variation in weaning critically ill adults from invasive mechanical ventilation. Ann Am Thorac Soc 2018;15:494-502.

44. Frat JP, Thille AW, Mercat A, et al. High-flow oxygen through nasal cannula in acute hypoxemic respiratory failure. N Engl J Med 2015;372:2185-96.

45. Frat JP, Brugiere B, Ragot $S$, et al. Sequential application of oxygen therapy via high-flow nasal cannula and noninvasive ventilation in acute respiratory failure: an observational pilot study. Respir Care 2015;60:170-8.

46. Lin $\mathrm{C}, \mathrm{Yu} \mathrm{H}, \mathrm{Fan} \mathrm{H}$, et al. The efficacy of noninvasive ventilation in managing postextubation respiratory failure: a meta-analysis. Heart Lung 2014;43:99-104.

47. Nava S, Hill N. Non-invasive ventilation in acute respiratory failure. Lancet 2009;374:250-9.

48. Ranucci M, Ballotta A, La Rovere MT, et al. Postoperative hypoxia and length of intensive care unit stay after cardiac surgery: the underweight paradox? PLoS One 2014;9:e93992.

49. Ozsancak Ugurlu A, Sidhom SS, Khodabandeh A, et al. Use and outcomes of noninvasive positive pressure ventilation in acute care hospitals in Massachusetts. Chest 2014;145:964-71.

50. Thille AW, Muller G, Gacouin A, et al. Effect of postextubation high-flow nasal oxygen with noninvasive ventilation vs high-flow nasal oxygen alone on reintubation among patients at high risk of extubation failure: a randomized clinical trial. JAMA 2019;322:1465-75.

Cite this article as: Sang L, Nong L, Zheng Y, Xu Y, Chen S, Zhang Y, Huang Y, Liu X, Li Y. Effect of high-flow nasal cannula versus conventional oxygen therapy and non-invasive ventilation for preventing reintubation: a Bayesian network meta-analysis and systematic review. J Thorac Dis 2020;12(7):37253736. doi: $10.21037 /$ jtd-20-1050 